\title{
Perceived Changes among Second-Stage Agricultural Teachers Following a Professional Development Experience in Ecuador
}

\author{
E. Gorter ${ }^{1}$, T. Sorensen ${ }^{2}$, J. Russell ${ }^{3}$, S. Taylor ${ }^{4}$,T. Henderson ${ }^{5}$
}

\section{Abstract}

This qualitative case study sought to explore changes in the perceptions of second stage (years 4-10) school based agricultural education teachers (SBAE) following a professional development experience in Ecuador. Experiential learning was utilized as a theoretical lens and the model of teacher change as an operationalized conceptual framework. Semi-structured one-on-one interviews were conducted, and transcripts analyzed for thematic content. Findings elucidated three emergent themes: change in classroom practices; change in personal and professional pursuits; and change in perceptions, beliefs, and attitudes. As a result of the experience, misconceptions were dispelled, new understandings of agriculture and natural resources were developed, confidence was increased, and a desire for more global engagement was communicated. Teachers expressed their desire to be more inclusive, encourage global engagement and citizenship among their students, and integrate more global concepts within their teaching practices. The findings have implications for the importance of holistic approaches to teacher development through international experiential learning, rather than just a focus on classroom teaching practices. To add to our findings, similar research with other teachers beyond second stage should be conducted. Also, research exploring the influence of international development activities on career commitment should be conducted.

\section{Keywords}

experiential learning, international, teacher change, training

1. Erin K. Gorter, Lecturer, Cal Poly State University San Luis Obispo, 1 Grand Avenue San Luis Obispo, CA 93407, ekthomps@calpoly.edu, https://orcid.org/0000-0002-3001-2251

2. Tyson J. Sorensen, Assistant Professor, Utah State University, 2300 Old Main Hill Logan, UT 84322, tyson.sorensen@usu.edu, https://orcid.org/0000-0003-2103-1669

3. Jana Russell, Graduate Student, The Pennsylvania State University, Armsby Building University Park, PA 16802, jlr896@psu.edu, https://orcid.org/0000-0001-9869-5397

4. Sierra Taylor, Graduate Student, Cal Poly State University San Luis Obispo, , 1 Grand Avenue San Luis Obispo, CA 93407, sitaylor@calpoly.edu, https://orcid.org/0000-0002-8546-3666

5. Thomas M. Henderson, Assistant Professor, California State University Chico, 400 West First Street Chico, CA 95929, tmhenderson@csuchico.edu, https://orcid.org/0000-0001-8191-7256 


\section{Introduction and Problem Statement}

Passel and Cohn (2008) estimated one in five people in the United States will be an immigrant by the year 2050. This demographic shift could impact school-based agricultural education (SBAE) in the United States, creating a need for global perspectives and cultural awareness within these educational settings. Additionally, in order to prepare a workforce able to tackle complex global issues agriculture will face, students must have contextualized global experiences (Applied Development Economics, 2019; Braskamp, 2008). Teachers therefore need to possess the knowledge necessary to teach global concepts to their students. One way is through global professional development opportunities. Despite few opportunities for teachers to travel internationally (Hurst et al., 2015; Thuemmel \& Welton, 1983), studies show international experiences can reinvigorate teachers in their career, augment their cultural awareness, and increase their confidence and autonomy (Sandlin et al., 2013; Stephens \& Little, 2008).

Although international professional development experiences may provide benefits to teachers (e.g., Bruening et al., 2002; Oh \& Nussli, 2014), little is known about these type of experiences on second stage teachers (i.e., years four-10) (Kirkpatrick, 2007). While second stage teachers across all disciplines are characterized as autonomous, competent, and desiring professional growth opportunities (Conway \& Eros, 2016; Draves, 2012; Eros, 2009), they also exit the profession at a rate of $6.8 \%$ per year (Goldring et al., 2014). Within SBAE, mid-career SBAE teachers have been identified as being less committed than other teachers (McKim et al., 2017). Smalley and Smith (2017) called for calculated professional development opportunities for SBAE teachers in this mid-career phase. Understanding the influence of international professional development experiences on second stage SBAE teachers can be important in addressing teacher attrition issues as well as ensuring a well-trained, globally competent scientific workforce in the future.

\section{Theoretical and Conceptual Framework}

This study of the influences of an international teacher professional development experience on teachers was viewed through the theoretical lens of experiential learning (Kolb, 1984). Based on the work of Dewey (1938) and others, experiential learning focusses on specific lived experiences upon which learners reflect and then act (e.g., change behavior) as a result of their reflections on the lived experience (Kolb, 1984). Research clearly supports the theoretical underpinnings of experiential learning in providing professional development activities to teachers that involve active learning experiences and reflection (e.g., Desimone, 2011). With this theoretical perspective in mind, teacher professional development should be viewed as a process of change that is unique to each teacher as they connect their own past experiences with their newly acquired professional development experiences.

Viewed through the lens of experiential learning, research supports the notion that teacher change is a gradual process. Research suggests that effective professional development 
experiences should employ collaborative and active learning strategies that expose teachers to actual practices and curriculum, provides them opportunities to practice, and enables them to reflect on their own teaching practices (Adey 2004; Guskey, 1985). Furthermore, other studies suggest that effective professional development programs should consist of more than just a one-time event with no follow-up or prolonged reflection (Guskey, 2000).

To operationalize the theory of experiential learning in the context of teacher professional development as a process of teacher change, we utilized the model of teacher change (Guskey, 2002) as a conceptual framework for this qualitative study. Guskey (2002) proposed a linear model for teacher change, explaining that teacher attitudes and beliefs ultimately change from professional development activities after reflecting upon improvements in student learning and implementing changes to their teaching practice (see Figure 1). According to Guskey (2002), meaningful teacher development should be developed with the target audience in mind. This study focused on a professional development event designed specifically for SBAE teachers, thus Guskey's (2002) framework was deemed an appropriate model to explore teacher change in the context of an international teacher professional development experience.

\section{Figure 1}

The Model of Teacher Change (Guskey, 2002) As a Conceptual Framework for the Study

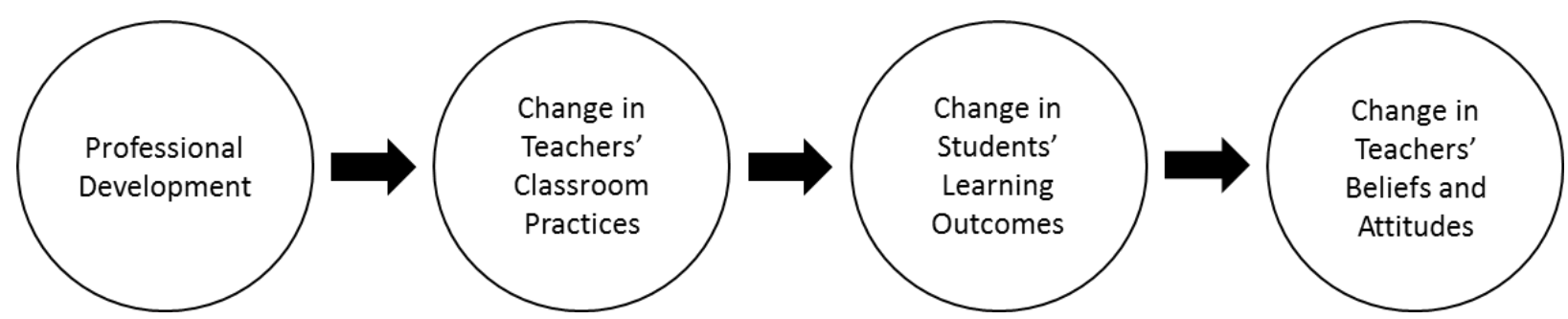

\section{Purpose}

The purpose of this study was to qualitatively explore changes in second stage teachers of SBAE from two western states who participated in an international experience specifically designed for the professional development of SBAE teachers. The following question drove this exploration: What changes occur in second stage SBAE teachers as a result of an international professional development experience?

\section{Methods}

This qualitative bounded case study was utilized to explore second stage teacher change as a result of a 10-day professional development program in Ecuador. We recruited SBAE teachers from California and Utah to participate in the professional development program. Participants were purposively selected for the study based on the criteria that they were SBAE teachers who 
had between four and 10 years of teaching experience and who were participants in the 2018 professional development program in Ecuador. Teachers who met the criteria were invited via email to participate in the study. Ultimately, six SBAE teachers agreed to participate.

One of the participants in the study was of Latino heritage while the other five were White. Five of the participants were female and one was male. Three participants had completed four years of teaching, two had completed six, and one had completed seven years of teaching. Each participant's school varied greatly in the percentage of Hispanic or Latino students, ranging from $11 \%$ to $94 \%$ with a mean of $55 \%$. Two of the participants had never travelled outside of the United States, one participant had extensive travel experience to Latin America where his family lived, and three participants had minimal travel experience outside of the United States. None of the participants had ever travelled internationally for work-related purposes.

The 10-day professional development program in Ecuador consisted of various agriculture and natural resources-based tours, cultural presentations, traditional and non-traditional educational presentations, curriculum development activities, home stays with local families, and reflection activities. Learning outcomes for the professional development program in Ecuador included: self-evaluation of local and global perceptions towards education, agriculture, natural resources, and culture; identify major social, political, food, environmental, educational, and agricultural issues and concerns facing Ecuador and Ecuadorian agriculture; develop goals and an action plan related to global education improvement; reflect on teaching practices regarding ELL students and integration of global concepts; and expand teaching skills and resources related to global agricultural, food, and the environment.

Data collection consisted primarily of one-on-one semi-structured interviews. The questions utilized in the semi-structured interviews were guided by various sources including the Global Perspectives Inventory (Research Institute for Studies in Education, 2017), Pulse of a Teacher Scale (Swan, 2005), and the Career Commitment Scale (Carson \& Bedein, 1994). Six different interviews lasting about 50 minutes each were conducted via telephone by the first two authors and transcribed verbatim for data analysis. The interviewing researchers also took hand-written notes on each interview guide during each interview and kept a research journal to record reactions, thoughts, and feelings.

We used constant comparative analysis to analyze the data (Merriam \& Tisdell, 2016; Saldaña, 2016). We analyzed and coded the data for thematic content using coding protocols outlined by Auerbach and Silverstein (2003). Two separate researchers performed the coding process separately with constant checks for accuracy and reliability in coding. Also, individual transcriptions were sent to the corresponding participants for informant feedback.

Multiple sources of input in the form of field notes, journals, and interview transcriptions reinforced trustworthiness. Researchers worked together in reviewing notes, audio recording, observations, and transcripts, and reflecting on the research process to support credibility and confirmability. Additionally, two of the researchers added credibility and confirmability through familiarity of the participants as they participated and provided leadership in the international 
experience themselves. To bolster transferability, we present multiple direct quotations that support the emergent themes (Schwandt et al., 2007).

\section{Findings}

Utilizing the model of teacher change (Guskey, 2002) as a framework for analysis, this study aimed at understanding what changes might occur in SBAE teachers as a result of an international professional development experience. Three major themes emerged with multiple sub-themes: (a) change in classroom practices (three subthemes); (b) change in personal and professional pursuits (three subthemes); and (c) change in perceptions, beliefs and attitudes (three subthemes); Pseudonyms were assigned to protect participant identity in reported findings.

\section{Theme 1: Change in Classroom Practices}

As a result of their international experience, the participants in this study expressed their desire to implement changes in their classroom practices; specifically: a) to be more inclusive of all students; b) to encourage students to engage in global opportunities and become better citizens; and c) to integrate more global agriculture and natural resources concepts including sharing their experiences from the Ecuador professional development program.

Most of the participants discussed how the experience made them want to increase inclusion and diversity within their teaching practice. Cara stated, "It has increased my desire to, to diversify the kind of students we have in our program." Mary mentioned how the experience has made her want to change her practice to be more inclusive. She said, "...especially for my students that come from different backgrounds, it made me want to try and cultivate different ways to be able to really help them and make my class the best experience possible for them." For some of the participants, the experience helped them understand their own students' backgrounds better to better meet their needs. Kelly said,

I think it has increased my awareness of others...their backgrounds and things that they value compared to my own...I'm more aware of how I approach certain situations or how I address certain questions or tone even when addressing, students of different cultures.

The Ecuador professional development experience enabled the participants to engage with the local people in their homes, which for some, seemed to be a humbling experience. Many of the participants expressed how it helped them gain a deeper appreciation for the values the Ecuadorian people cherished. As a result, participants expressed their desire to teach their own students about these values. Kelly stated,

I just felt like the things that the people in Ecuador valued was just, like, family, friendship, um, and I just felt like that experience is something that I can share with my own kids. Like, 'keep your word, be good to each other, be nice.' 
Molly discussed how she has more confidence talking to her middle-class students about being grateful and realizing what they have. She said,

It has definitely made me more comfortable to talk about topics that might be a little bit more uncomfortable for people, in regards to how people live. A lot of my students are white, kind of middle-class students. So, they don't realize how lucky they are to live the life that they do. So, it's definitely opened up doors for me to talk to them about it.

Participants also expressed their desire for their own students to have global experiences. Mary and Rose both talked about the benefit of international experiences and how it would benefit their students, just like it benefited them. Mary said, "I definitely would encourage any of my students that have the opportunity to go on an international experience...to take the opportunity and try to share my own experience and how it impacted me and my career and my life." Some participants talked about international experiences for students as a way to get them out of their comfort zone and how they wish they could provide similar experiences for their students as they had. Cara said,

I want my students to have the same experience somehow. I want them to take a trip outside of their comfort zone and see someplace new outside of the United States. One of the things I would love is just actually take a group of students on a trip like this. A trip to another country where they see agricultural being done in a way they hadn't imagined.

Participants in this study expressed their desire to integrate global concepts into their curriculum as a result of their experience in Ecuador. John stated, "Our students do need to be taught a global perspective. I really need to infuse global economies in my Economics class, I need to infuse a global view of agriculture all around, and not just focus solely on the US."

Similarly, Cara stated: "I've definitely been inspired to incorporate more of a global perspective in my classroom tremendously since then." The participants also shared how they connected global concepts from their Ecuador experience to their own curriculum by sharing pictures, personal experiences and stories. Rose said, "I reference it because I teach floral now. I wasn't previously, but I'm doing it this year. So, we visited a lot of the carnation farms, and roses and so I've used that experience in class." John talked about integrating pictures:

For about a week, we looked at the pictures, and we talked about my experience, um, and it's definitely inspired some of the students to try to, not necessarily go to Ecuador, but just expand their mindset, that there is no one way of doing things...that yes, in the US we do it this way, but it doesn't mean that it's the only way.

Kelly also talked about sharing pictures:

It has allowed me to share my experience with my students by showing them images or telling them stories and they seem rather interested because they feel like a lot of it they can relate back to because they've seen it, you know, when they've traveled in Mexico. 


\section{Theme 2: Change in Personal and Professional Pursuits}

As a result of their international experience, the participants in this study expressed changes in their personal and professional pursuits; specifically: a) re-evaluating their career choices; b) increased desire for additional international experiences; and c) gaining confidence to try new and uncomfortable things. The participants expressed great satisfaction and growth as a result of the Ecuador professional development experience. Some of the participants referred to it as "life changing" and "eye opening." As a result of the experience, some of the participants began questioning their career choice, wondering if a different career would enable them to have more international exposure. John stated,

It definitely has fulfilled a satisfaction, it also has inspired me to think about, 'should I do something else to continue this path of growth?' But I definitely have not made that decision final. It has instilled a passion and a satisfaction...it did start for me to wonder.

Participants also discussed their changes in attitudes towards international travel and how they want to do more of it in the future. Talking about international experiences, Mary stated, "It is definitely something that I want to experience more of and be able to see more." Molly talked about the desire to have international experiences, not as a tourist, but as one integrated into the local culture. She stated,

it has definitely made me really want to travel to a lot of different places, and instead of just go and travel and get the tourist experience, it really makes me want to emerge more in other people's culture and way of life, and not just walk around where maybe other people live, but to get the real experience, and you know, get to stay with the host family, it's definitely something that's really eye opening.

Rose discussed how she wanted to have additional international experiences with her students. She stated, "I want to travel more and try to bring that experience to the kids even maybe, to have them go abroad, like I've had other teachers say they've taken students abroad."

The participants frequently discussed how the Ecuador experience increased their confidence and comfort level to face some of their challenges and do difficult things. When asked about how the experience changed her, Kelly said, "I feel like I'm more open to try new things...I feel like I'm more eager and more comfortable with asking veteran teachers for help or learning from others." Similarly, Mary talked about how she feels more comfortable talking with others about culture. She said, "I feel more comfortable after going through the experience and especially sharing my culture with other people and encouraging my students to share experiences that they have with their own culture that may be unique or different."

\section{Theme 3: Change in Perceptions, Beliefs, and Attitudes}

The participants in this study expressed how their perceptions, attitudes, and beliefs changed as a result of their experience; specifically a) how misconceptions were dispelled; $b$ ) how agriculture and natural resource management was re-conceptualized; and c) how they gained a new perspective for teaching. A few of the participants discussed how the Ecuador experience helped them realize some of the misconceptions they had about other nations and people, particularly misconceptions derived from the media. Mary stated, 
It was a very eye-opening experience. You have a perspective of what the media portrays of what life looks like in other countries, and what you think it's going to be like. And actually, experiencing that and being able to see that it is a completely different picture, it was very interesting.

Similarly, Molly stated, I think that watching the news or reading articles about other countries, my perspectives have definitely changed in the way I think about making decisions or making assumptions about other countries and other cultures...So I think it makes you take a step back and maybe not believe everything you hear.

The participants also expressed how their perceptions changed about agriculture and natural resources as a result of the Ecuador experience. Cara talked about this change in perspective: It helped me redefine what I call sustainable. Before I went on that trip, if you asked me what was sustainable agriculture, I would have told you that it had to be economically stable, environmentally stable, and produce enough for it to be viable. After the trip I added a fourth thing, in order to be sustainable, it also has to be social, the cultural part of the community has to be sustainable. If you are not honoring the local social and cultural practices, whatever you're doing will not be stable in that area.

Mary talked about her shift in thinking in relation to how important it is to teach about global agriculture. She stated, "I realized how much more important it really is...you realize the importance of it, especially with sharing, teaching our students about global agriculture..."

The Ecuador experience seemed to change the participants' perceptions about life and teaching. They seemed to see life in a bigger picture and not get caught up in the little things. Cara said, "It just puts things into perspective, and I'm not going to sweat the small stuff." Molly discussed how the Ecuador experience helped her gain an appreciation for what she has and the country she lives in. She stated,

I think it's just a really great experience and it opens your eyes, and it's definitely life changing. Maybe not, in the way that everybody thinks it's going to be, but it just makes you really appreciate what you have, and it makes you appreciate the country we live in.

Kelly discussed a change in thinking about her lifestyle choices as a result of the experience. She said,

I think it's an eye opener and it has really made me evaluate my own lifestyles. I feel like I'm spoiled with all of the necessities and items and, you know, the convenience that I have here in America versus in other countries. So, it has made me really step back and look at the way I live my own daily life.

In summary, the findings of this study parallel the changes as described in the model of teacher change (Guskey, 2002). The Ecuador experience yielded changes in teachers' classroom practices, and changes in teachers' perceptions, beliefs, and attitudes. It also yielded changes in teachers' personal and professional pursuits and behaviors (see Figure 2). 
Figure 2

Visual Summary of Findings

\begin{tabular}{|c|c|}
\hline \multirow{3}{*}{$\begin{array}{l}\text { Ecuador Professional } \\
\text { Development } \\
\text { Experience }\end{array}$} & $\begin{array}{l}\text { Change in Classroom Practices } \\
\text { 1- More inclusive of all students } \\
\text { 2- Encourage global engagement, gratitude, and } \\
\text { citizenship } \\
\text { 3- Integrate global concepts and share global experiences }\end{array}$ \\
\hline & $\begin{array}{l}\text { Change in Personal and Professional Pursuits } \\
\text { 1- } \text { Reevaluation of career choices } \\
\text { 2- Desire for additional international experiences } \\
\text { 3- } \quad \text { Confidence to try new and uncomfortable things. }\end{array}$ \\
\hline & $\begin{array}{l}\text { Change in Perceptions, Beliefs, and Attitudes } \\
\text { 1- } \quad \text { Misconceptions dispelled } \\
\text { 2- } \\
\text { 3- } \\
\text { 3rifulture and natural resources reconceptualized } \\
\text { Derspective on life and teaching }\end{array}$ \\
\hline
\end{tabular}

\section{Conclusions, Discussion, and Recommendations}

The Ecuador professional development experience-initiated changes in participants. Two of the three emergent themes aligned with the model of teacher change (Guskey, 2002), specifically, changes in classroom practices as well as changes in attitudes and beliefs. While the themes from this study in large part aligned with the model of teacher change, the theme related to change in personal and professional pursuits did not seem to align. Guskey's (2002) model of teacher change focused primarily on teachers' professional practice, yet as a result of the international experiential learning event, the participants clearly communicated a broader sense of personal and professional development (e.g., reconceptualization of agriculture concepts, examination of personal core values and lifestyle) not related to classroom teaching. This finding has implications for the importance of more holistic approaches to second stage teacher development, rather than just a focus on classroom teaching practices.

With agriculture and natural resources challenges at the center of an ever-changing global economy, the participants in this study expressed a new understanding of agriculture and people in a global context. They expressed their desire to engage students and teach about agriculture and natural resource topics in a global context as well teaching students about the core values of life that should transcend borders. This finding suggests that international experiential learning events for second-stage teachers can be valuable for dispelling misconceptions and increasing knowledge, confidence, and resources related to global agriculture concepts. Based on these findings, we suggest state and national leaders examine the feasibility of conducting experiential learning opportunities (e.g., international agriculture 
tours) with a holistic approach to development (e.g., personal and professional development) and focused on global agriculture and natural resources issues for teachers.

While the Ecuador teacher professional development program seemed to elicit positive changes in teachers, it also seemed to expand their world view and sense of adventure. Participants expressed their desire to engage in other future international travel opportunities while also expressing their increased confidence to try new things and step outside their comfort zone more. While these are positive outcomes, it was somewhat concerning that the sense of adventure also caused some to re-evaluate teaching as a career choice. The participants perhaps struggled to reconcile international travel opportunities and teaching agriculture as mutually compatible activities. It is possible that international teacher professional development experiences do not actually increase second stage teacher's sense of career commitment. Further research should be conducted exploring these questions.

The participants in this study did not explicitly discuss changes in student learning outcomes. A limitation to this study was the inability to determine if participant changes made as a result of the international experience actually led to student learning gains. Future research should be conducted exploring this. Additionally, we recommend program leaders provide opportunities for continued reflection and observation to identify impacts through student learning outcomes. This study was focus solely on second stage educators from only two states. With variations in classroom demographics, norms, and career cycle stage, we recommend further research with teachers from different states as well as teachers beyond the second stage.

Overall, this study sought to determine changes in second stage teachers as a result of an international professional development program. Participants clearly expressed changes in classroom teaching practices, perceptions, beliefs, attitudes, and pursuits. The findings of this study contribute to the literature base by identifying the specific changes second stage SBAE teachers experienced as a result of an international professional development program.

\section{References}

Adey, P. (2004). Effective professional development: What have we learned from teachers of thinking? Gifted Education International, 19(1), 13-20. https://doi.org/10.1177/026142940401900104

Applied Development Economics. (2019). California agricultural industry cluster final report. Agriculture, Water, \& Environmental Technology Sector for the California Community College System. https://1gz6c0efazm205698t14pd5c-wpengine.netdna-ssl.com/wpcontent/uploads/2020/09/UPDATED-FINAL-CA-AG-Study-Final-Report-020419.pdf

Auerbach, C., \& Silverstein, L. B. (2003). Qualitative data: An introduction to coding and analysis. NYU press. 
Braskamp, L. A. (2008). Developing global citizens. Journal of College and Character, 10(1), 1-5. https://doi.org/10.2202/1940-1639.1058

Bruening, T. H., Lopez, J., McCormick, D. F., \& Dominguez, D. R. (2002). Active learning: The impact on students participating in an extended field trip to Puerto Rico. Journal of Agricultural Education, 43(4), 67-75. https://doi.org/10.5032/jae.2002.04067

Carson, K. D., \& Bedeian, A. G. (1994). Career commitment: Construction of a measure and examination of its psychometric properties. Journal of Vocational Behavior, 44(3), 237262. https://doi.org/10.1006/jvbe.1994.1017

Conway, C., \& Eros, J. (2016). Descriptions of the second stage of music teachers' careers. Research Studies in Music Education, 38(2), 221-233. https://doi.org/10.1177/1321103X16672607

Desimone, L. M. (2011). A primer on effective professional development. Phi Delta Kappan, 92(6), 68-71. https://doi.org/10.1177/003172171109200616

Dewey, J. (1938). Education and experience. Simon and Schuster.

Draves, T. J. (2012). Second stage music teachers' professional identifies. Contributions to Music Education, 39, 31-51. https://www.jstor.org/stable/24127243

Eros, J. (2009). The career cycle and the second stage of teaching: Implications for policy and PD. Arts Education Policy Review, 112(2), 65-70. https://doi.org/10.1080/10632913.2011.546683

Goldring, R., Taie, S., \& Riddles, M. (2014). Teacher attrition and mobility: Results from the 2012-13 teacher follow-up survey (NCES 2014-077). U.S. Department of Education. National Center for Education Statistics. https://nces.ed.gov/pubsearch/pubsinfo.asp?pubid=2014077

Guskey, T. R. (1985). Staff development and teacher change. Educational, Leadership, 42(7), 57-60. https://uknowledge.uky.edu/edp facpub/21

Guskey, T. R. (2000). Evaluating PD. Corwin Press.

Guskey, T. R. (2002). Professional development and teacher change. Teachers and Teaching: Theory and Practice, 8(3/4), 381-391. https://doi.org/10.1080/135406002100000512

Hurst, S. D., Roberts, T. G., \& Harder, A. (2015). Beliefs and attitudes of secondary agriculture teachers about global agriculture issues. Journal of Agricultural Education, 56(1), 188202. https://doi.org/10.5032/jae.2015.01188 
Kirkpatrick, C. L. (2007, April 10). To invest, coast or idle: Second-stage teachers enact their job engagement. [Paper presentation]. American Educational Research Association Annual Conference, Chicago, IL, United States. https://projectngt.gse.harvard.edu/files/gseprojectngt/files/clk aera 2007 paper to post.pdf

Kolb, D. A. (1984). Experiential learning: Experience as the source of learning and development. Prentice Hall.

McKim, A. J., Sorensen, T. J., Velez, J. J., \& Henderson, T. M. (2017). Analyzing the relationship between four teacher competence areas and commitment to teaching. Journal of Agricultural Education, 58(4) 1-14. https://doi.org/10.5032/jae.2017.04001

Merriam, S. B., \& Tisdell, E. J. (2016). Qualitative research: A guide to design and implementation (4th ed.). John Wiley \& Sons.

Oh, K., \& Nussli, N. (2014). Challenging, eye-opening, and changing U.S. teacher training in Korea: Creating experiences that will enhance global perspectives. Journal of the Scholarship of Teaching and Learning, 14(4), 67-87. https://doi.org/10.14434/v14i4.12764

Passel, J. S., \& Cohn, D. (2008). United States population projections 2005-2050. Pew Research Center.

Research Institute for Studies in Education. (2017). Global Perspective Inventory: Theoretical foundations and scale descriptions. lowa State University. https://www.gpi.hs.iastate.edu/documents/GPI\%20Theory\%20and\%20Scales.pdf

Saldaña, J. (2016). The coding manual for qualitative researchers (3rd ed.). Sage.

Sandlin, M., Murphrey, T. P., Lindner, J. R., \& Dooley, K. E. (2013). Impacts of a faculty abroad experience on teaching style and technology use in a college of agriculture and life sciences. Journal of Agricultural Education, 54(3), 186-197. https://doi.org/10.5032/jae.2013.03186

Schwandt, T. A., Lincoln, Y. S., \& Guba, E. G. (2007). But is it rigorous? Trustworthiness and authenticity in naturalistic evaluation. New Directions for Evaluation, 114, 15-25. https://doi.org/10.1002/ev.223

Smalley, S. W., \& Smith, A. R. (2017). Professional development needs of mid-career agriculture teachers. Journal of Agricultural Education, 58(4), 282-290. https://doi.org/10.5032/jae.2017.04282

Stephens, C. A., \& Little, D. (2008). Testimonies from four agricultural education student teachers related to completing an international student teacher experience in New 
South Wales, Australia. Journal of Agricultural Education, 49(3), 46-55. https://doi.org/10.5032/jae.2008.03046

Swan, B. (2005). The relationship between the 2004 Ohio State University Agricultural Education student teachers' learning style, teacher heart, and teacher sense of efficacy (Publication No. 3169264) [Doctoral dissertation, The Ohio State University]. ProQuest Dissertations \& Theses Global.

Thuemmel, W. L., \& Welton, R. F. (1983). Teacher education activity in international agriculture: a national assessment. Journal of the American Association of Teacher Educators in Agriculture, 24(2), 40-52. https://doi.org/10.5032/jaatea.1983.02040

(C) 2020 by authors. This article is an open access article distributed under the terms and conditions of the Creative Commons Attribution license (http://creativecommons.org/licenses/by/4.0/). 